\title{
Factors Influencing Group Decision Making Performance in a GSS Enabled Environment
}

\author{
Rawan T. Khasawneh", Emad A. Abu-Shanab \\ Information Technology College, Yarmouk University, Irbid, 21163, Jordan \\ *Corresponding Author: rawan.khasawneh77@yahoo.com
}

Copyright (C) 2013 Horizon Research Publishing All rights reserved.

\begin{abstract}
Group decision making is becoming a very common activity in human society all over the world. Business problems nowadays are increasingly involving interactivity that requires collective effort and detailed information shared by a group of people working together. This paper is concerned with measuring the impact of group members' gender and familiarity on group decision making performance. An experimental approach is adopted where a sample of students, who study at Yarmouk University in Jordan, performed a specific task using a GSS enabled environment. Results revealed that female-only groups have a better performance than male-only groups and groups with familiar members have a better influence on the quality of decisions made during group work. Conclusions, contributions and future work are reported at the end.
\end{abstract}

Keywords Group Support System, Group Decision Making, Gender, Familiarity, Experimental Test, Conceptual Model, Jordan

\section{Introduction}

Decision making is one of the most important activities which every person in any type of organization did on daily basis. The decision is either simple and made individually or complex and needs collective effort and intensive information [1]. Wittenbaum, Hollingshead and Botero indicated that groups using GSS have a better chance to share more information and produce more creative results especially that such systems encourage anonymity in order to reduce personal conflict and communication problems [2].

Group decision making refers to a situation in which a group of people is involved in the identification of alternatives, evaluation of these alternatives, and selection of the most appropriate one [3]. Group decision making can be done in three different degrees: consultative decision making, through which the group leader consults group members before making a decision. The second is consensus decision making, through which both the group leader and group members work together in generating alternatives, evaluating them and reaching the final decision. The third is democratic decision making, through which group members are empowered to make the decision [4].

The literature shows that group performance is affected by two types of attributes: readily detectable attributes that can be easily recognized in person (e.g., age, gender, etc.) and underlying attributes that can't be easily identified (e.g., personality characteristics, knowledge level, etc.). The focus of this paper is to measure the impact of gender and familiarity among group members on group decision making performance through conducting an experimental test in a GSS enabled environment.

The rest of the paper will be organized as the following: The next section summarized related work. Section 3 will describe the research methodology, the sample details and instrument used. Section four will depict data analysis and results, followed by a discussion and conclusions in section five.

\section{Background and Literature Review}

In today's business environment, group work is becoming an important strategy that all types of organizations should utilize and carefully build in order to leverage not only their work performance and efficiency but also to enhance decision making processes and outcomes [5]. Making decisions in groups using computerized systems (GSS) is preferred than traditional group decision making especially that these computerized systems can facilitate the capabilities of groups, enhance decision making process, and facilitate communication between group members which will enhance results and encourage innovation and creativity [6].

\subsection{Making Decision in Groups}

Decision making is a common human activity that is concerned with selecting the best alternative from two or more alternatives in order to achieve specific predefined goal $[7][8][9][10][11]$. Managers are dealing with decision making as an art that will lead to creative decisions with high 
quality [8]. Viewing decision making as an art is derived by the existence of three sets of factors that affect decision making: decision features, situational factors, and individual differences [12].

Furthermore, such view is supported by the availability of a wide range of methods, techniques and approaches which are helpful and useful for decision makers in order to make the proper decision on the right time using the right resources utilizing their knowledge and personal experiences [8]. Making decisions in groups is a participatory process in which multiple individuals are acting together in order to analyze the problem and select the best solution among several alternatives; it can be also described as a shared process [7][13].

It is important for all types of organizations to improve group decision making process and activities through using several methods and technologies that will make such process more efficient and effective [5] especially that most decisions in organizations nowadays are made by groups, teams or committees rather than individuals [14]. The literature indicates that making decisions in groups requires the existence of common decision making problem (group task) with a shared interest in a collective decision in addition to the existence of equal opportunity for all group members to influence the decision. Kolbe, Strack, Stein and Boos proclaimed that task structure, information requirements, and evaluation demands are three main characteristics through which a group task can be analyzed [15].

Lunenburg indicated that making decisions in groups needs a culture to be built and spread widely throughout the organization. This culture, as some scholars proposed, has four main phases. The first phase is "readiness" which is concerned with planning for moving toward group decision making and determining types of decisions to be shared, the participants in group decision making process and the extent of involvement. The second phase is called "experimentation" and focuses on building familiarity between members involved in group decision making process. The third phase is called "refinement", in which group decision making process begins and members start working together. The fourth phase is called "institutionalization" through which decision-making within/in groups becomes a norm in the organization and all members are involved in [16].

Making decisions in groups has several advantages that exceed the combined individual abilities, knowledge and expertise of the group members, but also leverage the group commitment to the result of decision making process [1][3]. Furthermore, making decisions by groups rather than individuals will result in greater sum of total knowledge, more suggested approaches to solve the problem, greater number of alternatives, increased acceptance of a decision and better understanding of a problem or a decision [3][11][16].

Group decision making is not the appropriate choice in all cases, where Lunenburg presented three of the most popular and useful models of decision making that help in determining when, how and to what extent group decision making is needed. These three models are: the Vroom-Yetton-Jago decision tree model, Tannenbaum and Schmidt's decision-making pattern choice model, and Nash's synergistic decision making model [17]. Also, group decision making can be done at three different levels: consultation level in which the leader seeks other members' opinions and then helshe makes histher own decision, delegation level in which leader empowers someone to behave in a specific manner in order to make certain decisions, and participation level that represents democratic behavior in decision making [11].

Even though group decision making has several advantages that encourage people to adopt such practice, it also has several disadvantages including: social pressure toward conformity and group think, individual domination, secondary goals conflict, ambiguous responsibility, wasted time and slower decision making [3][11][16].

\subsection{An Overview of Group Support System (GSS)}

The literature shows that group support systems or what was called previously group decision support systems can be defined as information technology-based systems that provide decision making support to groups in order to produce more suitable decisions [1][5][18] [19]. Aronson, Myers and Wharton indicated that the term GDSS is reduced by researchers to GSS because such systems were used generally to enhance group meeting performance that doesn't necessarily lead to decisions [5].

GSS can be used to describe any technology used to improve the quality of group decision making in order to make higher quality decisions, simulate useful interactions and reduce the negative aspects of small group decision making [20]. Furthermore, GSS provides help for decision makers who work together as a team through removing communication barriers, providing several procedures for structuring decision analysis and establishing a level of anonymity that will enhance the overall group performance [1]. Also, GSS supports the exchange of ideas, opinions and choices between group members through an easy to use interface that is available for all members in the group which has a significant impact on the quality of the final decision [18].

On the other hand, GSS can be characterized by several major characteristics such as: its ability to automate decision making sub processes using information technology tools, its design as special information system that helps in solving only one type of problems or a variety of group level decisions, and its ability to encourage idea generation and conflict resolution [21]. Khasawneh and AbuShanab concluded that the intention to use GSS is strongly affected by the system perceived ease of use and its perceived usefulness [22]. GSS has a significant impact on all decision processes that are related to information including: information recall, information exchange and information use. Such impact will result in sharing more information, 
generating creative ideas and enhancing group's overall performance [23].

\subsection{Gender and Familiarity Impact on Group Decision Making}

Research indicated that group decision making performance is affected by group diversity which have numerous dimensions and can be defined in terms of any factors that make a difference [24]. Researchers in the area of group decision making assert that there are several factors (personal and environmental) that affect the effectiveness of using group decision making regardless whether these groups use computerized system (GSS) in decision making processes or not. These factors include the following: task, type and composition of group, type of technology, culture, age, group structure (homogenous vs. heterogeneous), gender (male vs. female) and group member familiarity (familiar vs. unfamiliar) [6]. The focus of this project will be on the last two factors.

\subsubsection{Gender Impact on Group Decision Making}

Research related to the impact of gender differences on decision making is still ambiguous, where most cases indicate that females are affected more by the environment, they consume more time in decision making process, and they look for more details and information. Males tend to be more objective, realistic, assertive and dominant [25]. Furthermore, males prefer to be more competitive using winner-and-loser approach during decision making process while females are more likely to use collaborative and cooperative strategies [26]. Also, females are likely to become more intuitive, sensitive and looking for creative ideas and solutions compared with males who prefer to use their structural power to be the dominant during work. Based on that, gender differences have significant impact on the quality and creativity of final decisions made within groups [27].

On the other hand, females enjoy participating in group work and they focus on gaining trust and establishing relationships with others more than males who prefer to be more task-oriented during work. Studies indicated that trust is an important factor that influences the performance of virtual teams (team communicating through a virtual/electronic domain). The same study also concluded that ability, benevolence and integrity are the major predictors of trust within groups [28]. Also, females reported more satisfaction and better team development level in female-only teams compared with the satisfaction achieved by males in male-only teams [29] especially that Zaidi, Saif and Zaheer indicated that males liked to work with females in the same group and they become dissatisfied when they work in male-only groups [27].

Even though some research indicated that females compared with males, are kinder, more agreeable, more supportive of other members, and more cooperative in same-sex work group, Balliet, Li, Macfarlan and Vugt indicated that the environment and situation in which females and males want to make a group decision have a significant impact on how group members behave, interact and perform in group decision making process even if they work in same-sex group or not [30].

\subsubsection{Familiarity Impact on Group Decision Making}

Researchers can study familiarity in a group work from two different points of view; the first view focuses on the extent to which a decision problem is clear to decision makers and the second view focuses on synergy that exists between members in the same group [31]. This project will focus on the second view of familiarity through evaluating the impact of group member familiarity on group decision making processes and outcomes with a deep focus on the synergy and relationship existed between group members.

Familiarity among group members is an important factor for group meetings and decision making processes in both GSS and non-GSS enabled environment. Familiarity has a significant impact on group cohesion, meeting satisfaction and uninhibited communication among group members [32][33]. Also, Cumming indicated that there is a significant and positive relationship between prior familiarity of group members and their work performance and outcomes. Such positive relationship implies that greater familiarity between members within the same group makes the work more effective and helps members enjoy their work more [34].

Furthermore, familiarity among group members can be used as a method for reducing uncertainty through several ways. One of these ways depends on the expectation that implies the similarity of person's behavior in future interaction no matter the prior interaction between members was positive or negative [35]. Janssen, Erkens, Kirschner and Kanselaar discussed the impact of familiarity among group members and on group interaction and performance based on Tuckman's group development model that was proposed in 1965 and consists of four stages: forming, storming, norming and performing. Janssen and his colleagues expected that familiarity will lead to better group performance but such expectation was not confirmed in their research [36].

Research also explored familiarity impact on group decision making performance, where a significant relationship with group homogeneitylheterogeneity was the focus of such research. Regarding group homogeneity impact on group decision making, studies revealed contradictory results. King, Hebl and Beal highlighted that even though there are several studies supporting weak or no relationship between groups homogeneity and performance, other studies indicated the existence of such relationship in the way that heterogeneous groups performance is equal or better than the performance of homogenous groups over an extended period of time [37]. Another study concluded that group heterogeneity has a significant impact on the creativity and quality of decisions [27].

Similarly, Anniseh and yusuff portrayed two types of group decision making: heterogeneous and homogenous 
environments. The former type concerns with a situation in which decision making processes involve dissimilar individuals in term of personality, gender, age, expertise, backgrounds and other demographic treats. Also, heterogeneous groups have greater ability to perform their tasks more effectively than homogenous groups [7]. Vala et al. explored this issue within group diversity (homogenous vs. heterogeneous) and tried to understand the impact of group nature on group decision making processes and outcomes. The author concluded to the fact that homogenous groups perform better and produce more positive outcomes when they work on exploitation task, while heterogeneous groups perform better and produce better results when they work on exploration task [38].

\section{Research Methodology}

This study focused on exploring the influence of group members' gender and familiarity on the performance of group within a specific problem context. The following sections will describe the research model, the sample and sampling process, and the instrument used for measuring the constructs incorporated in the research model.

\subsection{Research Model}

Researchers in the area of GSS and group work presented two main types of general attributes that affect group performnace, these attributes are explored in the conceptual model depicted in Figure 1. In a try to fulfill the objectives of this paper, the focus will be only on one specific attribute from each general type, which are already discussed in the introduction and literature review sections, these specific attributes as described in Figure 2 are: gender and group members familiarity.

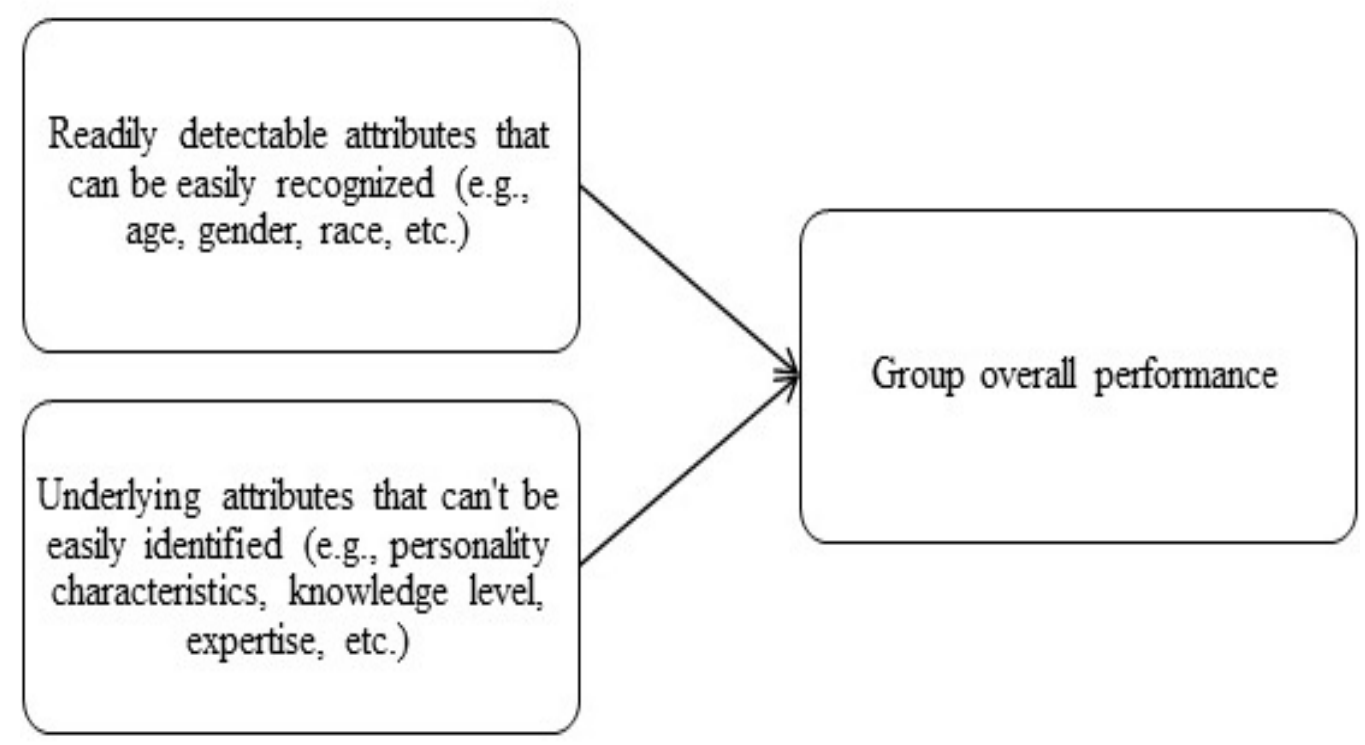

Figure 1. conceptual model

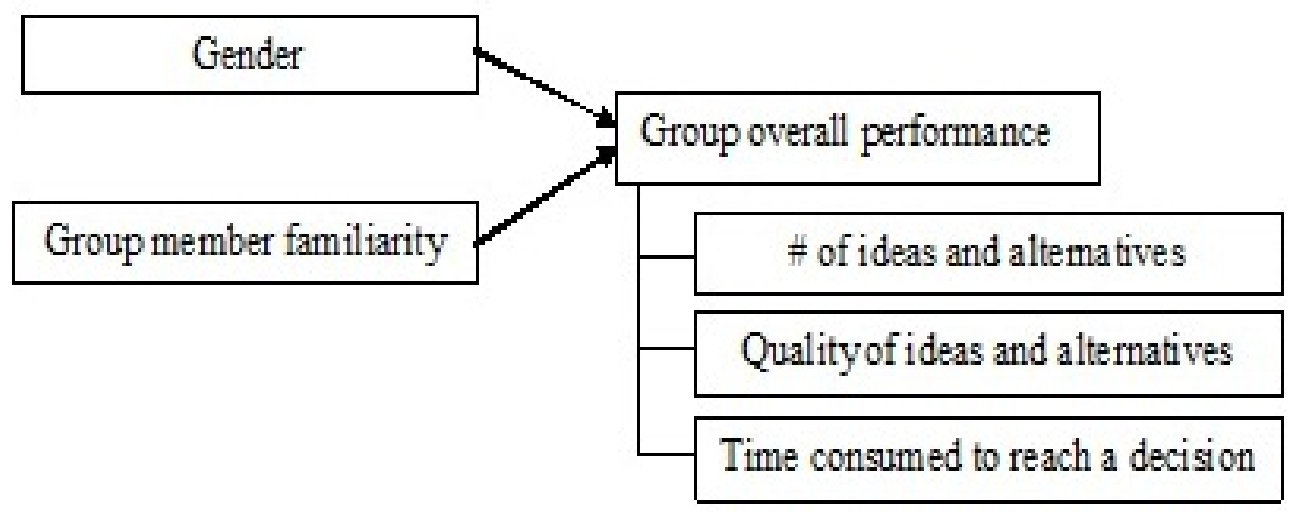

Figure 2. Reduced conceptual model 
As presented in the Figure 2, this paper will utilize one of the commonly used dependent variable "group overall performance" that is commonly used in the area of GSS. The dependent variable will be measured in term of: number of ideas and alternatives generated, quality of ideas and alternatives and time spent to make a decision.

The following is the major research question followed by the detailed hypotheses.

RQ1: What is the impact of gender and group familiarity on groups' overall performance?

H1: In a GSS enabled environment, female-only groups have better performance than male-only groups.

H2: In a GSS enabled environment, mix-sex groups have better performance than female-only groups.

H3: In a GSS enabled environment, mix-sex groups have better performance than male-only groups

H4: In a GSS enabled environment, groups with familiar members have a better influence on the quality of decisions made during group work.

\subsection{Sample and Sampling Process}

A convenient sample of 120 subjects was selected to be involved in this project (only 90 persons actually performed the test) and they were distributed into small groups according to the following classification treatment listed in Figure 3 with a total number of 30 groups. Each group consisted of three persons.

\begin{tabular}{|c|c|c|c|}
\hline & \multicolumn{2}{|c|}{ Group member familiarity } \\
\hline & & $\begin{array}{c}\text { Familiar group } \\
\text { member }\end{array}$ & $\begin{array}{c}\text { Unfamiliar group } \\
\text { member }\end{array}$ \\
\hline \multirow{3}{*}{$\begin{array}{l}\dot{\vec{v}} \\
\overrightarrow{0} \\
0\end{array}$} & $\stackrel{\star x}{\Sigma}$ & 5 groups & 5 groups \\
\hline & $\frac{0}{\pi}$ & 5 groups & 5 groups \\
\hline & $\begin{array}{l}\frac{0}{\pi} \\
\text { है } \\
0\end{array}$ & 5 groups & 5 groups \\
\hline
\end{tabular}

Figure 3. The distribution of groups

Subjects were students studying in the area of information technology at Yarmouk University (YU) in Jordan. The reason for selecting such sample group was the researcher's belief that their knowledge of web technology and its applications and their experience in using information systems would enable them to give valuable insights. Also, such sample can easily be managed within a classroom context, where meeting, grouping, and communicating with groups might be a challenge.

The researcher visited classes participating in the project and explained the purpose of the study and the process of conducting the experiment. Students participating in the experiment were given up to 5 extra grades in their corresponding courses based on their work performance as a motivation. The distribution of students among groups was done randomly, taking the group gender and familiarity into consideration (like homogeneity and heterogeneity construct).

\subsection{Experiment and Instrument Used}

In order to achieve the goal of this paper, an experimental test was done using one of the commonly used GSSs tools called WebEx. Subjects conducted a case analysis using a case scenario that needed group members to communicate and analyze this business situation. The details of their communication and collaboration were reported by groups at the end of the experiment.

Reports submitted were analyzed by a group of experts that consisted of five master students studying an MIS program. A session was conducted between the researchers and the expert group discussing the case and the guidelines of the analyses. Each expert evaluated the reports submitted to reach the following analyses results reported in the following section.

The dependent variable used by this project was measured using a self reported instrument described in the following table (Table 1). Both reports submitted by groups and the instrument filled were used for the analysis of results

Table 1. Measurement instruments

\begin{tabular}{|c|c|}
\hline Variable & Instrument \\
\hline Gender & $\begin{array}{r}\text { Gender plays a vital role in group work } \\
\text { (male vs. female) }\end{array}$ \\
\hline Group member familiarity & $\begin{array}{c}\text { It focuses on the synergy and } \\
\text { relationship existed between group } \\
\text { members (Familiar vs. unfamiliar) }\end{array}$ \\
$\begin{array}{c}\text { Group overall performance: } \\
\text { Number of ideas } \\
\text { Quality of ideas }\end{array}$ & $\begin{array}{c}\text { Instrument: } \\
\text { Counting ideas } \\
\text { Time consumed to reach a } \\
\text { decision }\end{array}$ \\
$\begin{array}{c}\text { Expert ratings: good, fair and bad } \\
\text { Measuring time consumed until } \\
\text { reaching a decision or stop generating } \\
\text { ideas and alternatives }\end{array}$ \\
\hline
\end{tabular}

\section{Data Analysis and Discussion}

Once the experimental test is done, reports from only 26 groups from 30 groups were received. These reports are evaluated and analyzed by experts; expert analysis included: counting the total number of ideas generated by each group, computing the time consumed until each group completed the task and reached a decision and finally evaluating the quality of the generated ideas. The total number of generated ideas is 104 .

Table 2 summarizes the results of experts analyses that were made on the male-only groups; the table shows that the total number of ideas generated was 28 ideas (quality of ideas were reported as: 11 ideas were good, 9 ideas were fair, and 8 ideas were low quality), Ideas generated included: 19 ideas generated by groups with familiar members consuming an average of 339 minutes, and 9 ideas by groups with unfamiliar members consuming an average of 281 minutes.

Table 3 summarizes the results of experts analyses that were made on the female-only groups; the table shows that the total number of ideas generated by them is 46 ideas 
(quality of ideas were reported as: 24 ideas were good, 12 ideas were fair and 10 ideas were low quality) including: 30 ideas generated by groups with familiar members during on average 228 minutes and 16 ideas by groups with unfamiliar members during on average 304 minutes.

Table 2. Male-only groups' performance analyses

\begin{tabular}{|c|c|c|c|c|}
\hline \multirow{2}{*}{ Grp. \# } & \multicolumn{2}{|c|}{ Familiar group members } & \multicolumn{2}{c|}{ Unfamiliar group members } \\
\cline { 2 - 5 } & $\#$ of ideas & $\begin{array}{c}\text { Time } \\
\text { consumed } \\
\text { (minute) }\end{array}$ & \# of ideas & $\begin{array}{c}\text { Time } \\
\text { consumed } \\
\text { (minute) }\end{array}$ \\
\hline 1 & 5 & 405 & 2 & 285 \\
\hline 2 & 5 & 360 & 1 & - \\
\hline 3 & 1 & 240 & 3 & 258 \\
\hline 4 & 5 & 510 & 3 & 300 \\
\hline 5 & 3 & 180 & - & - \\
\hline
\end{tabular}

Table 3. Female-only groups' performance analyses

\begin{tabular}{|c|c|c|c|c|}
\hline \multirow{2}{*}{ Grp. \# } & \multicolumn{2}{|c|}{ Familiar group members } & \multicolumn{2}{c|}{ Unfamiliar group members } \\
\cline { 2 - 5 } & \# of ideas & $\begin{array}{c}\text { Time } \\
\text { consumed } \\
\text { (minute) }\end{array}$ & \# of ideas & $\begin{array}{c}\text { Time } \\
\text { consumed } \\
\text { (minute) }\end{array}$ \\
\hline 1 & 5 & 195 & 3 & 240 \\
\hline 2 & 7 & 135 & 3 & 600 \\
\hline 3 & 8 & 480 & 4 & 360 \\
\hline 4 & 5 & 180 & 3 & 170 \\
\hline 5 & 5 & 150 & 3 & 150 \\
\hline
\end{tabular}

The analyses results mentioned above revealed that female-only groups have a better performance than male-only groups (H1 supported). Such result is in alignment with the findings of [27], where they concluded that females are likely to become more intuitive, sensitive and looking for creative ideas and solutions compared with males who prefer to use their structural powers to be the dominant during the process.

Table 4 summarizes the results of experts analyses that were made on the mix gender groups; the table shows that the total number of ideas generated by them is 30 ideas (quality of ideas were reported as: 14 ideas were good, 8 ideas were fair and 8 ideas were low quality) including: 11 ideas generated by groups with familiar members and 19 ideas by groups with unfamiliar members.

Table 4. Mix gender groups' performance analysis

\begin{tabular}{|c|c|c|c|c|}
\hline \multirow{2}{*}{ Grp. \# } & \multicolumn{2}{|c|}{ Familiar group member } & \multicolumn{2}{c|}{ Unfamiliar group member } \\
\cline { 2 - 5 } & \# of ideas & $\begin{array}{c}\text { Time } \\
\text { consumed } \\
\text { (minute) }\end{array}$ & \# of ideas & $\begin{array}{c}\text { Time } \\
\text { consumed } \\
\text { (minute) }\end{array}$ \\
\hline 1 & 3 & 150 & 1 & - \\
\hline 2 & 8 & 150 & 2 & 195 \\
\hline 3 & - & - & 4 & 420 \\
\hline 4 & - & - & 7 & 120 \\
\hline 5 & - & - & 5 & 300 \\
\hline
\end{tabular}

The report analysis results show that mix gender groups don't have better performance than male-only groups as experts' evaluation results indicated that mix gender groups consumed more time to generate few low quality ideas compared with male-only groups (H2 not supported). The same result applied when mix gender groups performance is compared with the performance of female-only groups (H3 not supported).

Also, the reports received indicated that groups with familiar members have a better influence on the quality of decisions made during group work (H4 supported). This result is compatible with a study conducted by [34]. Compared with unfamiliar group members groups with familiar members consumed more time in generating a good number of high quality ideas. [34] presented that the existence of positive relationship between prior familiarity of group members and their work performance and outcomes makes the work more effective and helps members enjoy their work more.

\section{Conclusion}

The goal of this paper was to measure the impact of gender and familiarity among group members on the group decision making performance using a sample of students, who study at Yarmouk University in Jordan. An experimental approach was used, where students performed specified task in a GSS enabled environment. Data collected was analyzed by experts and the analysis results revealed that female-only groups have better performance than male-only groups (H1 supported) and groups with familiar members have a better influence on the quality of decisions made during group work ( $\mathrm{H} 4$ supported) while $\mathrm{H} 2$ and $\mathrm{H} 3$ were not supported.

This research contributed to our knowledge in the area of group performance using electronic systems. The study utilized a sample of Jordanian subjects in an aim to explore the factors that affect group's overall performance keeping in mind that research in this area is relatively few. Experiential approach is requested to better understand the issues involved in group decision making. The study focused on two major predictors of group performance: gender and group members' familiarity. Studying group decision making is challenging for multiple reasons; it requires more complex data analysis methods, large sample size, devoted subjects that can survive the experiment and a clear variance within groups' and members related to the experiment details.

This work suffered from few limitations that need to be addressed in future work. The group size and number of groups need to be increased, where more groups are needed to account for deaths in research. Also, it is important to conduct a full fledge research that comprehensively cover more factors that influence group performance. Based on that, future research is needed to come up with more predictors that relate to GSS performance. Also, repeating the same experimental test with larger group size and in different contexts is needed. On the other hand, studying other factors that affect group overall performance such as culture and task type is required with a try to improve the reliability of instruments used. 


\section{REFERENCES}

[1] Elena, R., Dimitra, V. \& Konstantinos, K. (2011). Web Based Group Decision Making In Human Resources Management. Proceeding of the International Symposium on the Analytic Hierarchy Process, pp.1-6.

[2] Wittenbaum, G., Hollingshead, A. \& Botero, I. (2004). From Cooperative to Motivated Information Sharing in Groups: Moving Beyond the Hidden Profile Paradigm. Communication Monographs, Vol.71(3), pp.286-310.

[3] Buckley, P. (2012). Using Information Aggregation Markets for Decision Support. International Journal of Business Research and Management (IJBRM), vol.3(3), pp.133-143.

[4] Lunenburg, F. (2011). Decision Making in Organizations. International Journal of Management, Business, And Administration, vol.15(1), pp.1-9.

[5] Aronson, J., Myers, R. \& Wharton, R. (2000). Time Pressure Impacts on Electronic Brainstorming in a Group Support System Environment. Informatica, vol.24(2), pp.149-158.

[6] Abu-Shanab, E. (2006). Group Support Systems: A Culture-Task Fit Model. Proceeding of the Seventh Arab Conference on Information Technology (ACIT 2006), Irbid, Jordan, 1-6.

[7] Anisseh, M. \& Yusuff, R. (2011). A fuzzy group decision making model for multiple criteria based on Borda count. International Journal of the Physical Sciences, Vol. 6(3), pp.425-433.

[8] Ismail, S. (2011). The Role of Marketing Information System on Decision Making: "An Applied study on Royal Jordanian Air Lines (RJA)". International Journal of Business and Social Science, Vol. 2(3), pp.175-185.

[9] Jinbo, W., Xuefeng, L. \& Ming, D. (2011). A Framework of Knowledge Management System for Support Decision Making on Web-enabled Environment. Journal of Convergence Information Technology, Vol.6(7),pp.133-139.

[10] Lunenburg, F. (2010a). The decision making process. National Forum of Educational Administration And Supervision Journal, vol.27(4), pp.1-12.

[11] Hashim, F., Alam, G. \& Siraj, S. (2010). Information and communication technology for Participatory based decision-making-E-management for administrative efficiency in Higher Education. International Journal of Physical Sciences, Vol. 5(4), pp.383-392.

[12] Appelt, K., Milch, K., Handgraaf, M. \& Weber, E. (2011). The Decision Making Individual Differences Inventory and guidelines for the study of individual differences in judgment and decision-making research. Judgment and Decision Making, Vol. 6(3), pp. 252-262.

[13] Perez, I., Cabrerizo, F. \& Herrera-Viedma, E. (2011). A Mobile Group Decision Making Model. International Journal of Uncertainty, Fuzziness and Knowledge-Based Systems, Vol.19(1), pp.33-52.

[14] Lunenburg, F. (2010b). Group Decision Making: The Potential for Groupthink. International Journal of Management, Business, And Administration, vol.13(1), pp.1-6.

[15] Kolbe, M., Strack, M., Stein, A. \& Boos, M. (2011).
Effective Coordination in Human Group Decision Making: MICRO-CO: A Micro-analytical Taxonomy for Analyzing Explicit Coordination Mechanisms in Decision-Making Groups. A chapter in a book titled "Coordination in Human and Primate Groups", by: Margarete Boos, Michaela Kolbe, Peter M. Kappeler \& Thomas Ellwart, Springer-Verlag Berlin/ Heidelberg, 2011, pp.199-219.

[16] Lunenburg, F. (2010c). Group Decision Making. National Forum of Teacher Education Journal, vol.20(3), pp.1-7.

[17] Lunenburg, F. (2010d). Models of Decision Making. Focus on Colleges, Universities, And Schools, vol.4(1), pp.1-9.

[18] Ermatita, Z., Hartati, S., Wardoyo, R. \& Harjoko, A. (2011). Electre Methods in Solving Group Decision Support System Bioinformatics on Gene Mutation Detection Simulation. International Journal of Computer Science \& Information Technology (IJCSIT), Vol 3(1), pp.40-52.

[19] Arnott, D. \& Pervan, G. (2008). Eight key issues for the decision support systems discipline. Decision Support Systems, vol. 44, pp. 657-672. Available online at www.sciencedirect.com.

[20] [Carneiro, J., Laranjeira, J., Marreiros, G., Freitas, C. \& Santos, R. (2012). A Context-aware Model to Support Ubiquitous Group Decision Making. Journal of Internet Services and Information Security (JISIS), vol.2(1/2), pp.105-118.

[21] Ermatita, Z., Hartati, S., Wardoyo, R. \& Harjoko, A. (2012). ELECTRE-Entropy method in Group Decision Support System Modelto Gene Mutation Detection. (IJARAI) International Journal of Advanced Research in Artificial Intelligence, vol.1(1), pp.58-63.

[22] Khasawneh, R. \& Abu-Shanab, E. (2013). Factors Affecting Group Support Systems (GSSs) Usage: Users Perceptional View. The 4th International Conference on Information \& Communication Systems (ICICS 2013), Irbid, Jordan, April 23-25.

[23] Dennis, A. (1996). Information Exchange and Use in Group Decision Making: You Can Lead a Group to Information, but You Can't Make it Think. MIS Quarterly, vol.20(4),pp.433-457.

[24] Yaniv, I. (2011). Group diversity and decision quality: Amplification and attenuation of the framing effect. International Journal of Forecasting, vol.27, pp.41-49.

[25] Lizarraga, M., Baquedano, M. \& Cardelle-Elawar, M. (2007). Factors that affect decision making: gender and age differences. International Journal of Psychology and Psychological Therapy, vol.7(3), pp.381-391.

[26] Hannagan, R. \& Larimer, C. (2010). Does Gender Composition Affect Group Decision Outcomes? Evidence from a Laboratory Experiment. Political behavior, vol.32(1), pp.51-67.

[27] Zaidi, S., Saif, M. \& Zaheer, A. (2010). The effect of workgroup heterogeneity on decision making: An empirical investigation. African Journal of Business Management, Vol.4(10), pp.2132-2139.

[28] Furumo, K. \& Abu-Shanab, E. (2010). The Impact of Language Barriers on Communication and Trust Development in Global Virtual Teams. The International Conference on Business and Information 2010, July 5-7, 
2010, Kitakyushu, Japan.

[29] Furumo, K. \& Pearson, M. (2007). Gender-Based Communication Styles, Trust, and Satisfaction in Virtual Teams. Journal of Information, Information Technology, and Organizations, Vol.2, pp.47-60.

[30] Balliet, D., Li, N., Macfarlan, S. \& Vugt, M. (2011). Sex Differences in Cooperation: A Meta-Analytic Review of Social Dilemmas. Psychological Bulletin, vol.137(6), pp. 881-909.

[31] Nooraie, M. (2012). Factors Influencing Strategic Decision-Making Processes. International Journal of Academic Research in Business and Social Sciences. Vol.2(7), pp.405-429.

[32] Mukahi, T. \& Corbitt, G. (2004). The Influence of Familiarity among Group Members and Extraversion on Verbal Interaction in Proximate GSS Sessions. Proceedings of the 37th Hawaii International Conference on System Sciences, pp.1-9.

[33] Phillips, K., Northcraft, G. \& Neale, M. (2006). Surface-Level Diversity and Decision-Making in Groups: When Does Deep-Level Similarity Help? Group Processes
\& Intergroup Relations, vol.9(4), pp.467-482.

[34] Cumming, J. (2010). Student-initiated group management strategies for more effective and enjoyable group work experiences. Journal of Hospitality, Leisure, Sport and Tourism Education, vol.9(2), pp.31-45.

[35] Hinds, P., Carley, K., Krackhardt, D. \& Wholey, D. (2000). Choosing Work Group Members: Balancing Similarity, Competence and Familiarity. Organizational Behavior and Human Decision Processes, vol.81(2), pp.226-251.

[36] Janssen, J., Erkens, G., Kirschner, P. \& Kanselaar, G. (2009). Influence of group member familiarity on online collaborative learning. Computers in Human Behavior, vol.25, pp.161-170.

[37] King, E., Hebl, M. \& Beal, D. (2009). Conflict and Cooperation in Diverse Workgroups. Journal of Social Issues, Vol.65(2), pp.261-285.

[38] Vala, J., Drozda-Senkowska, E., Oberle, D., Lopes, D. \& Silva, P. (2011). Group heterogeneity and social validation of everyday knowledge: The mediating role of perceived group participation. Group Processes \& Intergroup Relations, vol.14(3), pp.347-362. 